\title{
Lalinha e Celeste: era uma vez o colonialismo
}

\section{Elisabete Peiruque*}

\begin{abstract}
Resumo: $\mathrm{O}$ artigo, ao analisar a narrativa sobre a vida em um campo de refugiados de Angola em Lisboa, aponta para o caos do mundo colonial após a descolonização e para a permanência das idéias que presidiram o colonialismo.
\end{abstract}

Palavras-chave: Colonialismo; Guerra colonial; Póscolonialismo.

\begin{abstract}
Through the analysis of the narrative about the life in a Angolan refugee place located in Lisbon, this article shows the chaotic colonial world after the independence war and also points out the persistence of imperialist ideas.
\end{abstract}

Keywords: Colonialism; Colonial World; Postcolonialism

Era uma vez o colonialismo... que pareceu, no primeiro momento de seu término, ter apenas sido encerrado como o descer do pano do palco sobre o final de uma peça, como se o regime colonial não tivesse mais nenhuma implicação com o que ficou para trás. Marc Ferro (1996, p. 180), em seu estudo sobre as colonizações, observa o longo tempo transcorrido até o momento em que se começou a mexer nesta ferida ainda aberta. $\mathrm{O}$ estado dramático dos países saídos do regime colonial não poderia mais ser ignorado em vista de suas conseqüências de amplitude mundial. Somente na década de oitenta teve início a revisão do que se pode chamar, talvez sem exagero, uma das grandes tragédias do planeta, pela sua repercussão até hoje entre os povos ex-colonizados, bem como pelo movimento de migração que passou a marcar o mundo, não como alguma coisa positiva mas, sim, representando a necessidade de sobrevivência de grandes massas de população. Por uma destas ironias da vida - afinal nem tão surpreendente tendo em vista o que antecedeu a diáspora dos povos colonizados - quando os nativos recuperaram das mãos dos colonizadores a posse de sua terra oprimida foram, em grande parte, obrigados a deixarem sua pátria, freqüentemente trocada pela terra do opressor, pela inviabilidade de lá viverem.

A leitura do conto de José Cardoso Pires, Por cima de toda a folha, datado de 1978, dá a medida da força do fato literário. Foi a literatura que iniciou a revisão do colonialismo? Talvez não de maneira categórica, mas, certamente, foi um dos seus elementos agenciadores

\footnotetext{
* Elisabete Peiruque é professora de Literatura Portuguesa na UFRGS.
} 
pela produção precoce de textos em relação à história. O que parecia ter sido encerrado como um fato banal ganha força com textos ficcionais que denunciam a verdade do sistema colonial. Homi Bhabha (1998, p. 33) anota a circunstância criada pelo pós-colonialismo em que as grandes migrações, suas conseqüências econômicas e culturais poderão vir a constituir o terreno para o discurso literário mundial, ao contarem "histórias transnacionais de migrantes, colonizados ou refugiados políticos”. O imaginário gerado por esta nova face do mundo, acrescida de outros fatores que vêm transformando a vida do planeta nas últimas décadas, precisa ser representado e é na literatura de ficção onde isto mais freqüentemente ocorre. Lévinas (cf. Bhabha, 1998, p. 38) considera o romance contemporâneo como aquela forma literária que, qual "arte-mágica", "vê a interioridade a partir da exterioridade". A ficção que preside tanto o romance como o conto permite ver nessa forma curta também a essência do romance. Os personagens, nas suas experiências pessoais, apontam para o contexto que as rodeia.

O conto de Cardoso Pires, ao relatar a vida de um local de refugiados da África em Lisboa após a independência de Angola e o recomeço das suas vidas, é a representação do que foi o momento pós-colonial com as suas antíteses. Por um lado, este tempo é marcado pelo caos do mundo ex-colonizado, sua miséria e injustiças postas à mostra. Por outro, deixa clara a permanência e a força das idéias que fizeram o colonialismo, principalmente aquilo que foi a sua marca característica, o racismo. Na narrativa literária, estas duas realidades concomitantes são representadas em cenas que mostram o horror da vida dos nativos nas colônias e a guerra colonial; ou são muitas as passagens que dão conta dos pensamentos dos retornados. No primeiro caso, leia-se a descrição que se faz da guerra e a ironia do narrador referindo-se ao modo como os negros eram vistos pelo colonizador:

enquanto lá embaixo o primo Amílcar, camionista de pesados, ficava a desafiar os negros de má-fome. Que eram mais que as mães, diga-se de passagem: negros a formigarem no capim, negros na pele do leão e na casca dos imbondeiros, negros turras-terroristas, olho aceso e pé no vento, a alastrarem pelas cidades; negros aos estilhaços; farrapos de negros a apodrecerem nos mastros. Guerrilhas, em suma. (PIRES, 1979, p. 123)

No segundo caso, a conversa das donas, refugiadas nostálgicas pela perda de sua condição de senhoras, é absolutamente irônica e elucidativa do momento. A África tornou-se inviável, mas há a saudade dos bons tempos da exploração pelo trabalho escravo.

E aquele melaço que a gente lá comia?

O próprio café, Dona Natividade. Há lá café que se compare com o angolano.

O mel, dona Lídia. Só aquela cor loirinha, Dona Lídia

As tâmaras, tão amarelas, tão docinhas. (PIRES, 1979, p. 145)

Voltando ao primeiro fragmento no qual se lê, entre outras, o desprezo pela raça considerada inferior, leia-se o que afirma Albert Memmi (1967, p. 68): “É significativo que o 
racismo faça parte dos colonialismos em todas as latitudes. Não é uma coincidência: o racismo resume e simboliza a relação fundamental que une colonizador e colonizado”. E mais adiante, mostra a ideologia do colonialismo ao dizer que "os europeus conquistaram o mundo porque sua natureza a isso os predispunha; os não-europeus foram colonizados porque sua natureza a isso os condenava" (MEMMI, 1967, p. 102). Suas palavras pontuais, escritas quando os impérios coloniais estavam desabando, dão conta da desculpa que seus governantes davam a si próprios para justificar a ocupação de terras que tinham dono: a inferioridade proclamada justificava o que se dizia ser a incapacidade dos nativos negros, árabes, e orientais para toda e qualquer coisa digna aos olhos do homem europeu. No conto em questão, há uma representação estética deste mundo conflitado, especificamente no contexto português. A ficção de José Cardoso Pires traz à tona a realidade brutal do regime, escamoteada pelo governo, e abre caminho para a revisão do processo histórico. A conversa das senhoras exiladas é um lamento pela perda de status que o branco colonizador ostentava sem o mínimo sentimento de culpa. Ou quem sabe nem tanto assim, e seja preciso esquecer. A lembrança das boas coisas da África exclui os que as produziam. Memmi aponta o problema mostrando a exploração do negro pelo branco colonizador, exploração absoluta fundada no desprezo e na desigualdade, garantidas pela força policial. "Não há dúvida, diz, que o colonialismo, para quem o viveu, é uma variedade do fascismo" (1967, p. 64).

No texto, Cardoso Pires, através de seu narrador, aponta para a força ainda viva deste discurso, quando algumas crianças do pequeno universo de refugiados, na esteira de seus pais e de toda a comunidade para ali transplantada, reproduzem as idéias racistas que 'justificaram' a dominação dos povos da África e da Ásia na partilha que os países europeus fizeram entre si nos anos oitenta do século XIX. O conto representa a denúncia de um perigo latente, já que as crianças de hoje poderão, como adultos de amanhã, encontrar caminho para pôr em prática um discurso que dê margem a que fatos semelhantes se repitam.

A parcela de revisão da história que o conto carrega vem por conta dos personagens que fazem o contraponto a este pequeno universo colonial deslocado. Tal contraponto para as idéias racistas e imperialistas é dado pela ação isolada da avó de Celeste, a única voz que se ouve contra o regime colonial, voz que é o ensinamento que a menina recebe para a vida. Contra os meninos Romeira que brincam de matar negros, Celeste e a avó defendem uma bonequinha de pano trazida da África, motivo de perseguição dos meninos brancos e de crítica por parte dos adultos. A boneca representa o negro na ambigüidade do discurso colonial, aquele de quem se necessita, mas que se despreza, e a sua presença, mesmo muda, constitui algo que incomoda. Culpa inconsciente ou consciente? A encantadora história de 
Celeste e sua boneca negra, Lalinha, narrada através de uma linguagem poética que reflete o olhar infantil seguidas vezes, constitui uma denúncia deste tempo e espaço em que se desrespeitou a figura do Outro, tempo que o colocou como objeto, impondo-lhe o silêncio da aceitação. "O Outro perde seu poder de significar" (BHABHA, 1998, p. 59). Nas palavras de Bhabha, o discurso colonial é contraditório porque o colonizador "reconhece a diferença [do colonizado] e simultaneamente a recusa ou mascara" (1998, p. 119). Mais do que contraditório, o discurso colonial primou pela desumanidade, e a literatura dá conta disto.

Bhabha (1998, p. 126) mostra a realidade representada por este discurso em que se ignora a figura do colonizado como ser humano. "O negro é ao mesmo tempo selvagem (canibal) e ainda o mais obediente e digno dos servos (o que serve a comida); ele é a encarnação da sexualidade desenfreada e, todavia, inocente como uma criança; ele é místico, primitivo, simplório e, todavia, o mais escolado e acabado dos mentirosos e manipulador das forças sociais". As senhoras, que de forma irônica são chamadas de donas, 'candidamente', dão conta também dos primeiros momentos pós-coloniais, quando não se cogita de uma revisão do colonialismo.

O texto literário, ao mostrar através das vozes das crianças duas posturas frente ao discurso colonial, aponta para as duas grandes possibilidades do mundo que está por vir: esse mundo será o da inclusão ou da exclusão. Como texto literário, não dá a resposta. Apenas mostra a realidade, deixando ao leitor a reflexão. Quase três décadas depois, vemos, sim, uma revisão do colonialismo, de maneira a não deixar dúvidas sobre o que foi, tornando evidente que nada poderá justificá-lo. As feridas que ficaram para sempre indeléveis entre os povos que sofreram a colonização ainda estão abertas, e a herança vem se perpetuando até os dias de hoje. Grande parte do contingente de excluídos que marcam a sociedade global é proveniente do mundo colonizado. Homi Bhabha (1998, p. 326), na esteira de Fanon, comenta o significado de ser negro no mundo colonizado e pós-colonizado. "não apenas um negro, mas um membro dos marginalizados, dos deslocados, dos diaspóricos”.

Da mesma forma que em muitos outros romances portugueses, no conto de José Cardoso Pires, a história irrompe, através da superfície ficcional do texto, quebra a parede de silêncio e, através dos estilhaços, deixa ver a verdade. Celeste, ao ver as luzes da cidade de Lisboa, identifica-a como uma ilha que o narrador diz em seu lugar ser a Cidade Imperial, numa visão irônica do dito Império, chamando a atenção, por sua vez, para a suposta escolaridade oferecida aos colonizados, obrigados a entender Portugal como seu país. Albert Memmi, numa visão que é a dos momentos finais do colonialismo, consegue ver o absurdo do mundo colonial em todas as suas facetas. Aquela da educação, inexistente a maior parte do 
tempo, configura isto que está internalizado também na pequena Celeste, filha e neta de colonizador. Nativa, portanto. A idéia de Império carrega consigo a de grandeza, idéia imposta aos negros colonizados em detrimento de tudo o que era seu. Ainda de acordo com Memmi (1967, p.95), livros escolares contendo histórias de crianças com nomes europeus brincando na neve constituíam o conteúdo dos parcos ensinamentos que lhes eram ministrados, quando isto acontecia. Isto significa o que foi realmente uma das ações do colonialismo: privar o colonizado de seu passado e de sua cultura, eliminar a sua identidade.

A negação da liberdade às colônias por parte do governo do Estado Novo amparou-se na falsa idéia de igualdade entre os portugueses e os negros das colônias. Idéia que aquele fazia passar, através de propaganda ideológica, onde, como num espelho, todos seriam iguais, ver-se-iam iguais. A resistência à independência das colônias, por conta de uma arcaica idéia de Império, mostra Portugal ancorado nas premissas do colonialismo do século XIX. O discurso de um certo Sir Merivale (cf. BHABHA, 1996, p. 144), proferido em 1839 na Inglaterra, mostra-se vivo e ressurge na ação do Estado Novo na guerra colonial. "A moderna imaginação colonizadora concebe suas dependências como um território, jamais como um povo". Para o Estado Novo, as colônias eram tão portuguesas quanto o Algarve e o Minho e, ignorando intencionalmente a noção de povo e tudo que ela contém, a igualdade não entrava na conta. A fala das donas e a dos homens do bar Quibala apontam para a realidade. Um dos homens do bar indaga de Celeste sobre quem lhe deu a boneca negra e revida que só pode ser afilhada, filha não.

\footnotetext{
"Tens então uma filha preta, formiguinha?"

(Celeste acenou que sim).

"Verdade, Formiguinha?"

Garra Cinzenta arreganhou os dentes: A mãe se calhar é que não sabe.

"Sabe, pois", disse a pequena Celeste. A minha mãe é que pediu ao Menino Jesus no Natal que me desse esta boneca.

"Não acredito, disse o Charuto resplandescente. "A tua mãe não ia te dar uma filha preta. [...]

"Isto que trazes aí não pode ser tua filha. Quando muito, afilhada, disse o Fraca Figura. "E mesmo assim nunca fiando”. (PIRES, 1979, p. 131)
}

Igualmente, as senhoras mostram a impossibilidade de uma boneca negra viver entre eles e muito menos ir à escola.

\footnotetext{
"E tu queres levar à boneca quando fores para a escola?", tornou a Dona da casa.

Celeste fez que sim muitas vezes.

"E se lá não houver pretinhas, já pensaste? Sabes que aqui não é como Angola, há poucos pretinhos" (PIRES, 1979, p. 145).
}

As falas destes personagens trazem à tona o desmentido da propaganda oficial. Igualmente se pode ver no horror que sentem pela visão da boneca uma forma de autoacusação - em nível inconsciente? - pelo que foi feito. Singularmente, o fato de um dos 
personagens ser uma boneca, portanto, muda, remete para a circunstância que o colonialismo criou em que o nativo não é ouvido, não é sequer visto.

Bhabha (1998, p. 111) conceitua o discurso colonial como "um aparato que se apóia no reconhecimento e repúdio das diferenças raciais/culturais/históricas". A passagem em que é relatada a ação do soldado, representado por um certo primo Amilcar a matar enlouquecidamente, acentua a visão do negro como não-gente, elemento descartável que se reproduz no momento mesmo de sua morte.

A ironia do narrador tem a função de denúncia, mostrando a visão que o branco colonizador tinha do negro. Portadora da voz do autor, a ironia que se 'ouve' na voz que conta aparece duplicada.

A animalidade do negro, como uma história que se gosta de repetir (BHABHA, 1998, p. 120) é dada pela conversa dos meninos Romeira que apontam de forma terrível para o mundo que nos aguarda, caso os muitos Romeiras consigam o poder. Os meninos Romeira são o futuro, e este, caso não seja extirpado o discurso da falsa superioridade racial, será dos racistas que continuam a não enxergar a diversidade racial e cultural. A avó e Celeste lutam contra o mundo racista, e a ação da avó é internalizada pela menina quando esta ganha da mãe uma boneca loura a cujos encantos nem a avó resiste: “Apesar de esperar uma nova boneca, a velha, ao ver aquela figurinha de Natal, ficou enternecida. Parecia um encanto dos anjos, só lhe faltava falar; ainda por cima vinha em folhos de renda, sapatos de verniz" (PIRES, 1979, p. 168). E então o discurso da justiça, e, portanto de condenação do colonialismo rege as palavras do narrador que expressa, onisciente, o ensinamento que Celeste recebe da avó. "Manalalinha e Manazabel eram unidas e irmãs como a noite é do dia" (PIRES, 1979, p. 168). As duas bonequinhas partilham o afeto de Celeste que não lhes vê diferença, remetendo para o imaginário de um mundo melhor. Mundo de menos excluídos, pelo menos mundo em que haja o direito de cada um "tornar-se aquilo que se quer ser, e não assumir alguma identidade pré-moldada que é simplesmente reprimida" (EAGLETON cf. BHABHA, 1998, p. 332). Para o universo dos refugiados, a boneca deve ser suprimida. O negro incomoda - é a mensagem mas a verdade é que não se pode dispensá-lo.

Rastreando os idos do colonialismo e o discurso que o amparava, Marc Ferro (1996, p. 11) afirma a "consciência pesada" que impera hoje. Não mais o colonizador é visto como aquele que cultivava a terra, trabalhava e era obrigado a defender-se dos agressores, dos rebeldes e de outros canalhas. A pouca simpatia com que os meninos Romeira são vistos através do tom sarcástico do narrador aponta para esta consciência. O colonizador, concretização da ideologia colonialista, não tem desculpa. Todorov (1999, p. 298), discutindo 
a questão do Outro na sua história da conquista da América, afirma categoricamente que não se pode desculpar os europeus pelos crimes perpetrados contra outros povos em nome de uma pseudo-superioridade auto-atribuída. Qualquer tentativa de justificativa - pois há quem ache hoje que o colonialismo não foi tão maléfico como se diz - é desmentida, pelo que se sabe e que o discurso literário mostra de maneira contundente. A brincadeira e a conversa dos meninos Romeira desmente de imediato a farsa de uma igualdade e de um ato de desprendimento por parte dos colonizadores, quando um deles fala em colecionar orelhas de negros ou refere a afirmação de seu pai a respeito das negras cujo sexo teria formigas. $\mathrm{O}$ mais puro desrespeito ao Outro, associado à crueldade, estão por toda a parte na história do colonialismo.

Para os que hoje consideram que o mundo colonial é coisa do passado, que infelizmente não se pode reverter o tempo e que "não temos culpa", que sejam lembradas as palavras de Bartolomeu de Las Casas que Todorov (1999, p. 297) vê como uma profecia: "Creio que por causa dessas obras ímpias, criminosas e ignominiosas, perpetradas de modo tão injusto, tirânico e bárbaro, Deus derramará sobre a Espanha sua fúria e ira, porque toda a Espanha, bem ou mal, teve o seu quinhão das sangrentas riquezas, usurpadas à custa de tanta ruína e extermínio”. Como não poderia deixar de ser, Todorov estende estas reflexões feitas há cinco séculos para toda a Europa ocidental.

Como texto literário, e, portanto ambíguo, a história de Celeste e Lalinha também permite pensar que os meninos Romeira possam vir a aprender com a ação decisiva e justa da avó de Celeste. Em termos metafóricos, no universo infantil está o futuro. Bom ou mau.

\section{Referências}

BHABHA. Homi K. O local da cultura. Belo Horizonte: UFMG, 1998.

FERRO, Marc. A história das colonizações. São Paulo: Companhia das Letras, 1996.

MEMMI, Albert. Retrato do colonizado precedido pelo retrato do colonizador. Rio de Janeiro: Paz e Terra, 1967.

PIRES, José Cardoso. Por cima de toda a folha. In: O burro em pé. Lisboa: Moraes Editores, 1979.

TODOROV. Tzvetan. A conquista da América - A questão do outro. São Paulo: Martins Fontes, 1999. 